\title{
Bilateral adrenal tuberculosis diagnosed by endoscopic ultrasound-guided fine-needle aspiration cytology
}

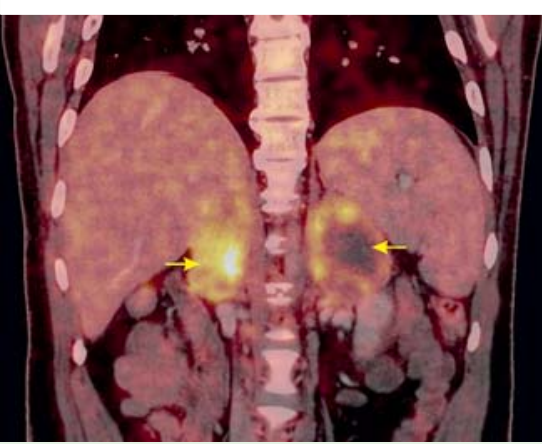

Fig. 1 Positron emission tomography - computed tomography scan showing the uptake in both adrenal glands (arrows).

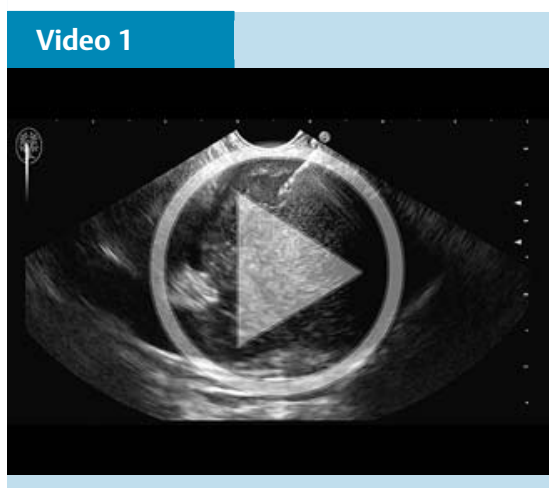

Endoscopic ultrasound-guided fine-needle aspiration of the left adrenal gland.

A 35-year-old patient presented with a 1-month history of fever, fatigue, and loss of weight and appetite. Clinical examination was unremarkable except for hypotension $(90 / 60 \mathrm{mmHg})$. The cause of fever could not be ascertained from routine investigations. Biochemistry results were: serum albumin $2.8 \mathrm{gm} / \mathrm{dL}$, international normalized ratio 1.4 , serum cortisol $4 \mu \mathrm{g} / \mathrm{dL}$, serum sodium $122 \mathrm{mEq} / \mathrm{L}$, and serum potassium $5.8 \mathrm{mEq} / \mathrm{L}$.

A contrast-enhanced abdominal computed tomography (CT) scan showed bilateral adrenal enlargement. Positron emission tomography (PET)-CT showed uptake only in the adrenal glands on both sides ( Fig.1). Endoscopic ultrasound (EUS) showed a $5 \times 4 \mathrm{~cm}$ well-defined, hypoechoic, left adrenal mass, with a definite outline ( $\bullet$ Fig.2a). The right adrenal gland showed a $4 \times 3 \mathrm{~cm}$ mass ( $\bullet$ Fig. 2 b) EUS-guided fine-needle aspiration (FNA)

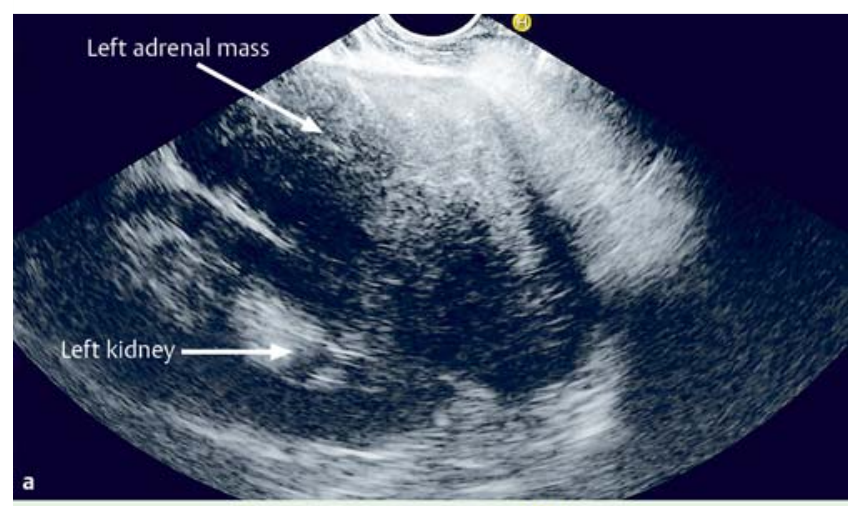

Fig. 2 Endoscopic ultrasound images. a Left adrenal mass. b Right adrenal mass.
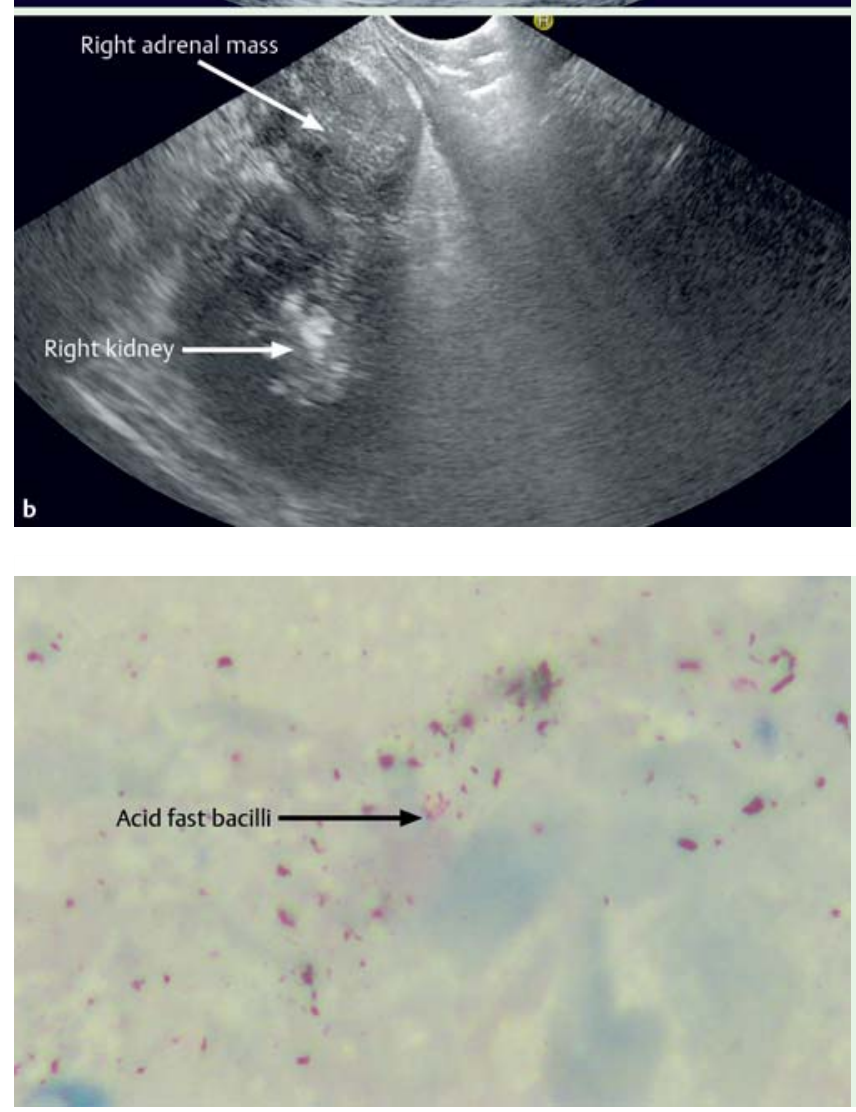

Fig. 3 Acid-fast bacilli against a background of necrotic cells. was performed on the left adrenal gland (๑ Video 1 ).

Cytology revealed numerous acid-fast bacilli against a necrotic background ( $\bullet$ Fig.3). A diagnosis of adrenal insufficiency secondary to tuberculosis was made, and treatment with corticosteroids for adrenal insufficiency and antitubercular therapy was started. Patient symptoms showed improvement within 2 weeks. Differential diagnosis of bilateral enlarged adrenal glands includes infections such as tuberculosis, histoplasmosis, neoplastic masses (malignant metastases, adrenal carcinoma, pheochromocytoma, lymphoma), and autoimmune disease (Addison's disease) [1,2]. Tissue diagnosis can be undertaken by ultrasound, CT or EUSguided FNA of adrenal glands. Various approaches have been used for ultrasound and CT-guided adrenal sampling. Complications occur in $2.8 \%-8.4 \%$ of cases and include adrenal hematoma, pneumothorax, perinephric hemorrhage, pain, 
needle-tract metastasis, and pancreatitis [3]. EUS-guided adrenal FNA has emerged as a safe alternative to ultrasound and CT-guided adrenal FNA [4]. Advantages of the EUS-guided approach include proximity to the left adrenal gland thus avoiding passage through other organs, realtime monitoring of needle passage, and high accuracy for adrenal identification. The accuracy of transabdominal ultrasound for adrenal identification is $70 \%$ for the left adrenal gland and $90 \%$ for the right gland [5]. Hence, complication rates are lower with EUS-guided FNA than with percutaneous approaches [5].

Endoscopy_UCTN_Code_CCL_1AF_2AZ

\section{Competing interests: None}

\section{Malay Sharma, Amol Patil,} Piyush Somani

Department of Gastroenterology, Jaswant Rai Speciality Hospital, Meerut, India

\section{References}

1 Gupta P, Bhalla A, Sharma R. Bilateral adrenal lesions. J Med Imaging Radiat Oncol 2012; 56: 636-645

2 Larbcharoensub N, Boonsakan P, Aroonroch R et al. Adrenal histoplasmosis: a case series and review of the literature. Southeast Asian J Trop Med Public Health 2011; 42: 920 925

3 Welch TJ, Sheedy PF, Stephens DH et al. Percutaneous adrenal biopsy: review of a 10-year experience. Radiology 1994; 193: 341 - 344

4 Eloubeidi MA, Seewald S, Tamhane A et al. EUS-guided FNA of the left adrenal gland in patients with thoracic or GI malignancies. Gastrointest Endosc 2004; 59: 627-633

5 Bodtger $U$, Vilmann P, Clementsen $P$ et al. Clinical impact of endoscopic ultrasoundfine needle aspiration of left adrenal masses in established or suspected lung cancer. J Thorac Oncol 2009; 4: 1485-1489
Bibliography

Dol http://dx.doi.org/ 10.1055/s-0042-111321

Endoscopy 2016; 48: E246-E247

(c) Georg Thieme Verlag KG

Stuttgart · New York

ISSN 0013-726X

\section{Corresponding author} Malay Sharma, MD

Department of Gastroenterology Jaswant Rai Speciality Hospital Meerut PIN-250 001

Uttar Pradesh

India

Fax: +91-121-2657154

sharmamalay@hotmail.com 